\title{
Evaluation of $F_{1}$ cows sired by Brahman, Boran, and Tuli bulls for reproductive, maternal, and cow longevity traits
}

\author{
Carl T. Muntean," Andy D. Herring,* David G. Riley," Clare A. Gill,* Jason E. Sawyer, ${ }^{*} \dagger$ and \\ James O. Sanders*
}

*Department of Animal Science, Texas A\&M University, College Station, TX 77843; and 'Texas A\&M AgriLife Research-McGregor Center, McGregor, TX 76657

\begin{abstract}
This study evaluated reproductive, maternal performance, and longevity traits of 143 $\mathrm{F}_{1}$ cows sired by Brahman (Br), Boran (Bo), or Tuli (T) bulls from Angus or Hereford cows from 1994 to 2011. Cow traits were measured at $7 \mathrm{yr}$ of age in 1999 and 2000 for 1992- and 1993-born cows, respectively. From 2004 to 2010, excluding 2008, incisor condition (solid, broken, smooth) scores were assigned to cows remaining in production; scores were evaluated with two models. Broken and solid mouths were each assigned a score of " 1 " and smooth assigned " 0 "; Br-sired (0.76) and Bo-sired cows (0.71) had higher scores $(P<0.05)$ than $\mathrm{T}$-sired cows $(0.54)$. When solid mouths were scored 1 and smooth and broken scored 0, Br-sired cows (0.34) were higher than T-sired (0.01) $(P<0.05)$, and Bo-sired $(0.23)$ cows were not different from either $(P>0.05)$. Age level of the cow within birth year was important for all modeled calf traits $(P<0.05)$. Birth weights were not different among cow inheritance $(P>0.05)$. Cow type influenced $(P<0.05) 205-\mathrm{d}$ adjusted weaning weight of calves; Br-sired dams $(228.1 \pm 2.37 \mathrm{~kg})$ produced the greatest weaning weight, followed by Bo-sired $(213.7 \pm 3.10 \mathrm{~kg})$, and T-sired $(201.6 \pm 2.69 \mathrm{~kg})$ dams $(P<0.05)$.

Adjusted means for calving rate for Bo-sired $(0.92 \pm 0.02)$ cows were higher $(P<0.05)$ than Br-sired $(0.86 \pm 0.02)$ and T-sired $(0.86 \pm 0.02)$ cows. Adjusted mean weaning rate was greater $(P<0.05)$ for Bo-sired cows $(0.86 \pm 0.02)$ than for cows sired by $\mathrm{Br}(0.77 \pm 0.02)$ bulls, but weaning rate for T-sired cows $(0.80 \pm 0.02)$ were similar $(P>0.05)$. Cow weight was greater $(P<0.05)$ for Br-sired cows $(590.5 \pm 8.35 \mathrm{~kg})$ than for Bo-sired $(505.8 \pm 10.46 \mathrm{~kg})$ or $\mathrm{T}$-sired cows $(508.5 \pm 9.37 \mathrm{~kg})$. $\mathrm{BCS}$ at weaning for 7-yr-old cows was similar $(P=0.08)$ for Br-sired and Bo-sired cows and lower for T-sired cows $(P=0.0005$, condition scores 6.0, 6.3, and 5.8, respectively). Boran-sired cows were older when they were removed from the herd, on average $(12.7 \pm 0.74 \mathrm{y}, P=0.03)$ than T-sired (10.6 $\pm 0.61 \mathrm{y})$; Br-sired cow persistence was intermediate and not different $(11.05 \pm 0.60$ y, $P>0.06)$ from the others. Boran-sired cows had higher calving and weaning rates and better mouth scores than the other groups; consequently, they had greater longevity as well. Boran-sired and T-sired cows were moderate in size and weighed less than Br-sired cows throughout the study. Tulisired cows weaned the lightest calves and had the most tooth deterioration as they aged.
\end{abstract}

Key words: Boran, Bos indicus, Brahman, longevity, maternal traits, reproductive traits, Tuli

(C) The Author (s) 2018. Published by Oxford University Press on behalf of the American Society of Animal Science. All rights reserved. For permissions, please e-mail: journals.permissions@oup.com. J. Anim. Sci. 2018.96:2545-2552 doi: $10.1093 /$ jas/sky169

\section{INTRODUCTION}

As of January 2017, there were approximately 31.2 million beef cows in the United States, and of

Received January 18, 2018.

Accepted May 9, 2018. those, nearly 7.5 million are in production in just 6 southern states in the United States (TX, LA, MS, AL, GA, and FL; USDA, 2017). It is apparent that a significant number of cows are present in the southern United States for beef production, and Bos indicus-influenced cattle have long been 
standard in this region. Cartwright (1980) explained that the American Brahman has been utilized almost exclusively in the United States for crossbreeding purposes for this region and purpose. It had also been the only $B$. indicus breed maintained in significant numbers in the United States until 1980 (Paschal et al., 1991). Although beef production in the southern United States relies heavily on $B$. indicus-influenced cattle, alternative sources of tropically adapted beef cattle have not been well characterized for use in the United States (Phillips et al., 2005). This limited diversity of tropically adapted breeds, and the poor characterization of alternatives, led us to evaluate other breeds for utilization in the southern United States. Boran and Tuli, breeds of cattle from Ethiopia and Zimbabwe, respectively, have shown to offer more heat tolerance than Hereford, but not as much as Brahman (Gaughan et al., 1999); thus, the objective of this study was to evaluate $F_{1}$ cows sired by Brahman, Boran, and Tuli bulls from Angus and Hereford cows for important traits to cow-calf production. Understanding the opportunity for these other tropically adapted breeds in crossbreeding systems in the United States as alternatives to the Brahman could provide value to beef producers in the southern United States.

\section{MATERIALS AND METHODS}

\section{Animals and Management}

All animal procedures were in accordance with the recommendations of the Guide for Use of Agricultural Animals in Teaching and Research (FASS, 2010). Data from $143 \mathrm{~F}_{1}$ Brahman-Hereford, Brahman-Angus, Tuli-Hereford, Tuli-Angus, BoranHereford, and Boran-Angus cows born in 1992 (66) and 1993 (77) at the Texas A\&M AgriLife Research Center at McGregor were used to evaluate reproductive, maternal performance, and longevity traits. Mature Angus and Hereford cows were bred by AI using semen of 9 Tuli, 7 Boran, and 16 Brahman bulls. Boran and Tuli semen was imported from Australia, and semen from Brahman bulls considered representative of the breed in the early $1990 \mathrm{~s}$ was obtained from purebred breeders and commercial breeding services. Distribution of these $F_{1}$ cows is presented in Table 1. Herring et al. (1996) reported birth, weaning, and postweaning performance of the animals in this study as well as carcass characteristics of the steer mates from the same matings. Heifer calves born to AI sires from Angus or Hereford dams were weaned and developed under a common protocol and exposed to bulls to calve as $2 \mathrm{yr}$ olds.
Subject cows were bred natural service to different breeds of bulls in different years throughout the study, but within a given year, all females were bred to the same breed of sire (Table 2). From 1995 to the end of the study, cows were comingled and provided equal access to the bulls. Bulls were exposed to cows in early to mid-May and were removed in mid- to late-July each year. A bull:cow ratio of 1:20 was the goal each year, but the ratio never exceeded 1:25 in any year of the study. Bulls were assessed for breeding soundness each year prior to turning out with cows. Calves were born from approximately February 15 to May 5 each year and were weaned in October or November at approximately 7 mo of age. Before 14 yr of age, cows were culled after 2 failures at any time to conceive or wean a calf. After cows were $14 \mathrm{yr}$ of age, they were culled for any failure to have or wean a calf, regardless of their previous record. Other reasons for culling included severe injuries, poor health, and poor udders (large or pendulous udder/teats that would hinder the ability of future calves to nurse).

\section{Traits}

Calf birth weight was recorded for each calf born in the study within $48 \mathrm{~h}$ of birth. Male calves

Table 1. Distribution of the $F_{1}$ cows by sire and dam breed

\begin{tabular}{lllr}
\hline \hline & \multicolumn{2}{c}{ Dam breed of cow } & \\
\cline { 2 - 3 } & Angus & Hereford & Total \\
\hline Sire breed of cow & & & \\
Boran & 15 & 21 & 36 \\
Brahman & 24 & 31 & 55 \\
Tuli & 23 & 29 & 52 \\
Total & 62 & 81 & 143 \\
\hline
\end{tabular}

Table 2. Cow mating summary

\begin{tabular}{lll}
\hline \hline Mating year & Cow birth year & Sire breed \\
\hline 1993 & $1992^{1}$ & Angus \\
1994 & $1993^{1}$ & Angus \\
1994 & $1992^{2}$ & Brangus \\
$1995^{3}$ & 1992 and $1993^{2}$ & Brangus \\
1996 & 1992 and 1993 & $\mathrm{~F}_{1}$ Hereford-Brahman \\
1997 & 1992 and 1993 & $\mathrm{~F}_{1}$ Brahman-Angus \\
1998 & 1992 and 1993 & $\mathrm{~F}_{1}$ Angus-Brahman \\
1999 & 1992 and 1993 & 3/8 Nellore-5/8 Angus \\
2000 & 1992 and 1993 & $\mathrm{~F}_{1}$ Nellore-Angus \\
2001 to 2002 & 1992 and 1993 & 3/8 Nellore-5/8 Angus \\
2003 to 2011 & 1992 and 1993 & Angus \\
\hline
\end{tabular}

\footnotetext{
${ }^{1}$ Bred as yearling females.

${ }^{2}$ Two-yr-old females.

${ }^{3}$ Cows were comingled in the same pastures and provided equal access to bulls from 1995 forward.
} 
were castrated when birth measures were recorded. At weaning, calves were weighed and assigned a BCS as an indicator of fatness or body composition of the calf ( 1 to 9 scale, $1=$ emaciated, $9=$ obese). Adjusted 205-d weaning weight was calculated according to Beef Improvement Federation (2010) guidelines within sex: adjusted 205-d weaning weight $=([$ weaning weight - birth weight $] /$ weaning age) $\times 205+$ birth weight + age of dam adjustment. At weaning each year, cow BW was recorded, and BCS (1 to 9, as above) were assigned.

Values of 1 were assigned to cows that calved or weaned a calf (for calving and weaning, respectively); values of 0 were assigned to those that did not.

From 2004 to 2010 (excluding 2008), in addition to palpation for pregnancy, incisor condition of cows was evaluated with subjective scores. Females with no teeth loose or missing were designated "solid," females with one or more teeth loose or missing were designated as "broken," and those with small, very deteriorated incisors, or no incisors at all, were designated as "smooth" (Riley et al., 2001). Although incisor condition score was collected as 3 levels, it was analyzed as a binary trait (and in 2 different models) of all females remaining in the study. Characteristics of the traits of this study are shown in Table 3.

Due to unforeseen circumstances, a small set of cows, and their records, were removed from the study. In 1994, 11 cows (all 1992-born cows) that were open at the end of the breeding season were bred by Simmental bulls from a neighboring pasture. All sire of cow breeds were represented among these 11 cows (6 T-sired, $3 \mathrm{Br}$-sired, and 2 Bo-sired). These cows calved in the fall of 1995 with calves by these Simmental bulls and raised these calves until weaning. Because these were fall calves, and out of Simmental bulls rather than the Brangus bulls the other 1992-born cows were bred to, they were removed from the weaning weight analysis. Their dams also received a 0 for their palpation in the fall of 1994, and they were held open (to get them back on the spring calving schedule for this project), and all records removed for 1995 so that they were not penalized.

\section{Statistical Analysis}

Analyses of all traits in the study (calving and weaning rate, calf birth weight, calf weaning weight, cow weight, cow BCS, and cow incisor condition score) except cow survival and reasons cows left the project were conducted using animal models with ASReml 3 (Gilmour et al., 2009). The pedigree included 4 generations; there was modeled relatedness among the Brahman sires, but not among the Boran nor Tuli sires with daughters in this project. Fixed effects investigated were sire breed of cow, dam breed of cow, age in years [categorized as modifications of recommended age classifications (BIF, 2010) for cow age: 2, 3, 4, 5 to 10, and 11 and older], year of record, and all possible interactions. Lactation status was investigated as a fixed effect in

Table 3. Descriptive statistics of data

\begin{tabular}{|c|c|c|c|c|c|}
\hline Item & $n$ & Mean & SD & Minimum & Maximum \\
\hline Calving rate $^{1}$ & 1,350 & 0.89 & 0.31 & 0 & 1 \\
\hline Weaning rate ${ }^{1}$ & 1,274 & 0.84 & 0.37 & 0 & 1 \\
\hline Birth weight, kg & 1,348 & 34.77 & 5.32 & 12.27 & 61.82 \\
\hline Weaning weight, $\mathrm{kg}^{2}$ & 1,270 & 220.58 & 34.33 & 111.36 & 327.27 \\
\hline Weaning BCS & 1,160 & 5.15 & 0.42 & 4 & 6 \\
\hline Cow weight, $\mathrm{kg}^{3}$ & 105 & 495.35 & 75.53 & 275.0 & 715.45 \\
\hline Cow $\mathrm{BCS}^{3}$ & 105 & 4.84 & 0.56 & 4 & 6 \\
\hline Age cow left herd, $\mathrm{yr}^{4}$ & 143 & 11.32 & 4.47 & 2 & 19 \\
\hline \multicolumn{6}{|l|}{ Incisor condition ${ }^{5}$} \\
\hline Model $1^{6}$ & 259 & 0.84 & 0.36 & 0 & 1 \\
\hline Model $2^{7}$ & 259 & 0.35 & 0.47 & 0 & 1 \\
\hline
\end{tabular}

${ }^{1}$ Proportion of cows that gave birth and weaned a calf of those that were exposed to bulls in the respective breeding season.

${ }^{2}$ Weaning weight reported as adjusted 205-d weight.

${ }^{3}$ Cow weight and condition score are represented for the year 2001 when cows were 8 and 9 yr.

${ }^{4}$ The age of the cow when she was removed from the herd is the age left herd.

${ }^{5}$ Incisor condition was scored as a binary trait with 2 different models where simple means were calculated. Cows missing no incisors were called solid mouth, those missing one or more incisors were called broken mouth, and those with no incisors remaining were called smooth mouth.

${ }^{6}$ Broken and solid mouths were scored a 1 and smooth mouths 0 .

${ }^{7}$ Solid mouths were scored a 1 and broken and smooth mouths 0 . 
analyses of cow weight and BCS. The direct additive genetic effect and residual were random. Calf birth weight included sex of calf and age of dam as fixed effects. In analyses of calf traits, likelihood ratio tests did not support the inclusion of maternal additive genetic effects $(P>0.5)$. However, the maternal permanent environmental effect was included $(P<0.05)$ for both birth and weaning weight and may account for some of the maternal additive genetic variance. Breed comparisons were carried out within the context of this variance parameterization. These traits were modeled as binomial distributions, and a logit link function was applied to data for analysis and testing. Means are presented after applying the inverse link function to results. Probability values of differences of least squares means were adjusted using Bonferroni correction for multiple testing; significance was called at $P$ values of $0.0011,0.0009,0.0025$, and 0.17 for reproductive rate, calf weight, cow weight and $\mathrm{BCS}$, and mouth score mean comparisons, respectively. Cow survival was analyzed with the LIFETEST procedures of SAS (SAS Inst. Inc., Cary, NC); survival curves were estimated for sire breed groups. Incisor condition scores $(n=259)$ were analyzed using 2 different models. The first grouped together all cows that had any incisors (assigned value of 1) and compared with those without incisors (value of 0 ). The second grouped cows that had all incisors (value of 1) and compared with those with any incisors missing (value of 0). Fixed effects were sire breed of cow, age category level of the cow, and birth year; the direct genetic additive effects and residual were random effects. Proportions of cows in each breed group that exited or left the project for various causes were tested against $\chi^{2}$ expectation using the FREQ procedures of SAS. Reasons for cow removal from the herd were summarized and presented in categories by cow sire breed group.

\section{RESULTS AND DISCUSSION}

\section{Calving Rate and Weaning rate}

Differences due to sire breed of cow were found for calving rate $(P=0.04)$ and weaning rate $(P=0.03)$. Table 4 shows that Bo-sired females were different from $\mathrm{Br}$-sired and $\mathrm{T}$-sired cows $(P=0.02$ and $P=0.03$, respectively), but $\mathrm{Br}$-sired and T-sired cows were not different from one another $(P=0.77)$. Boran-sired cows also weaned a higher percentage of calves $(P=0.01)$ than Br-sired cows, but neither Bo-sired nor Br-sired females were different
Table 4. Means $\pm \mathrm{SE}$ for reproductive traits by sire breed

\begin{tabular}{lcc}
\hline \hline Sire breed & Calving rate & Weaning rate \\
\hline Boran & $0.92 \pm 0.018^{\mathrm{a}}$ & $0.86 \pm 0.023^{\mathrm{a}}$ \\
Brahman & $0.86 \pm 0.020^{\mathrm{b}}$ & $0.77 \pm 0.024^{\mathrm{b}}$ \\
Tuli & $0.86 \pm 0.020^{\mathrm{b}}$ & $0.80 \pm 0.024^{\mathrm{a}, \mathrm{b}}$ \\
\hline
\end{tabular}

${ }^{\mathrm{a}, \mathrm{b}}$ Within traits (columns), means that do not share a common superscript differ $(P<0.05)$.

$(P>0.05)$ from $\mathrm{T}$-sired cows, although the difference between Bo-sired and T-sired females for weaning rate approached significance $(P=0.07)$.

Differences associated with the age category level of the cow nested within birth year were also detected for calving rate (Fig. 1). The 1992and 1993-born cows had calving rates above $85 \%$ as $2 \mathrm{yr}$ olds, but as $3 \mathrm{yr}$ olds, the 1992-born cows decreased calving rate to less than $50 \%$. A similar, but less drastic decrease in calving rate was seen in the 1993-born cows as they aged from 3 to 4 yr old ( $0.91 \pm 0.04$ to $0.74 \pm 0.05$, respectively). For all age groups of cows, both 1992- and 1993-born cows, calving rates were above $70 \%$ except for the 1992born cows as $3 \mathrm{yr}$ olds $(0.50 \pm 0.07$ in 1995).

Freetly and Cundiff (1998) did not find differences due to sire breed of cow $(P>0.05)$ in their study of heifers sired by $\mathrm{Br}, \mathrm{Bo}$, and $\mathrm{T}$ bulls from Angus and Hereford dams. In that study, females were evaluated under 2 different nutritional levels, and no significant differences in proportions pregnant were attributed to sire breed, dam breed, or nutritional level, although the same trend as in the current study was reported $(0.92,0.89$, and 0.80 , respectively, for Bo-sired, $\mathrm{T}$-sired, and $\mathrm{Br}$-sired heifers). Similarly, Cundiff et al. (2000) found no differences $(P>0.05)$ in calving rates of $F_{1}$ females by Bo, Br, and $\mathrm{T}$ bulls $(0.931,0.928$, and 0.901 , respectively). Chase et al. (2004) reported that $\mathrm{Br}$-sired cows had lower calving percentages than T-sired cows over a 6 -yr period $(89.0 \%$ and $94.7 \%$, respectively), although they were not significantly different.

Cundiff et al. (2000) reported that sire breed of cow was not a significant source of variation for weaning rate and observed adjusted means of $0.843,0.862$, and 0.841 for Br-sired, Bo-sired, and $\mathrm{T}$-sired cows raising their second and subsequent calves starting as $3 \mathrm{yr}$ olds and ending as $7 \mathrm{yr}$ olds. Chase et al. (2004) found breed type to be important $(P<0.01)$ in an evaluation of Brahman-Angus, Senepol-Angus, and Tuli-Angus cows having their second and subsequent calves by Charolais bulls and reported means for $\mathrm{Br}$-sired and $\mathrm{T}$-sired cows that 


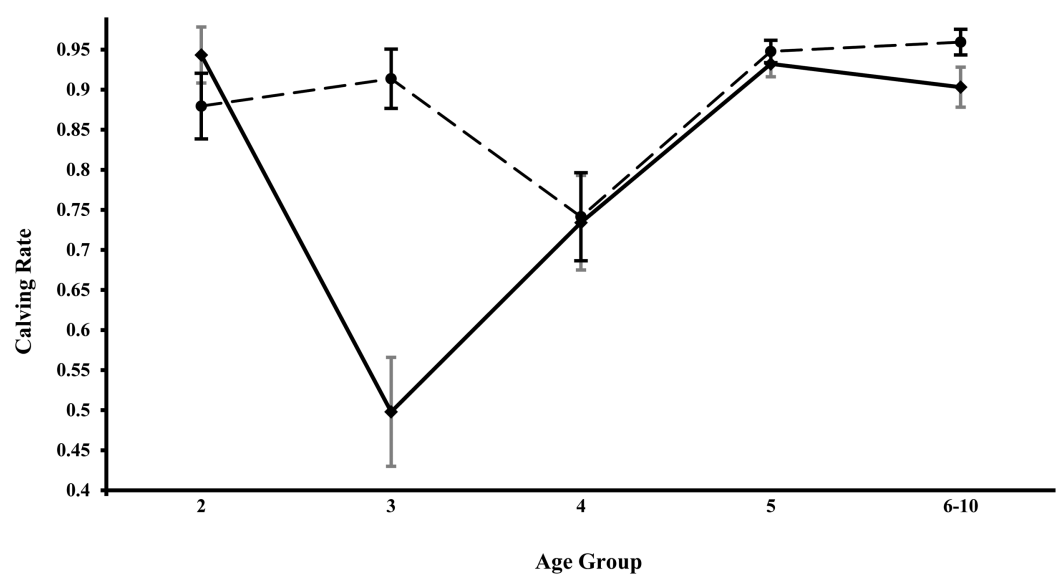

Figure 1. Calving rate by year of birth and age group of their dam. The solid line represents cows born in 1992, and the dashed line represents cows born in 1993 .

were not different from one another $(P>0.05)$ of (0.861 and 0.865 , respectively). Hetzel (1988) noted that in straightbred cattle in East and Southern Africa, weaning rates of $82 \%, 69 \%$, and $63 \%$ were observed in $\mathrm{T}$, Bo, and $\mathrm{Br}$ cows, respectively.

\section{Calf Weight}

Birth weight. Sire breed of cow and dam breed of cow were not important sources of variation in birth weight ( $P=0.83$ and 0.46 , respectively); birth weights were $33.96 \pm 0.53,33.55 \pm 0.63$, and $33.75 \pm 0.58 \mathrm{~kg}$, for calves from Br-sired, Bo-sired, and T-sired, respectively (Table 5). Cundiff et al. (2000) found average birth weights slightly higher than in the current study, but still with no differences $(P>0.05)$, for calves from Br-sired, Bo-sired, and T-sired females $(37.3,37.0$, and $38.4 \mathrm{~kg}$, respectively).

Differences associated with the birth year $\times$ age group of the cow interaction were also detected for calf birth weight $(P<0.01)$. The lightest calves were born to 2-yr-old females (30.97 \pm 0.64 and $30.06 \pm 0.61 \mathrm{~kg}$, respectively, for 1992- and 1993born cows), and the heaviest were born to 5 to 9 yr olds $(36.25 \pm 0.41$ and $36.74 \pm 0.38 \mathrm{~kg}$, respectively, for 1992-and 1993-born females). There were significant differences between the calves born to 2-yr-old cow groups vs. 5- to 9-yr-old cow groups $(P<0.05)$, but no differences were detected between 1992- and 1993-born cows within each cow age group $(P=0.29$ and 0.33 , respectively, for 2 -yr-old cow groups and 5- to 9-yr-old cow age groups). In both the 1992- and 1993-born cows, birth weights of their calves decreased from the 5- to 9-yr-old cow group $(36.25 \pm 0.41$ and $36.74 \pm 0.38 \mathrm{~kg})$ to the $10+$-yr-old cow group $(33.82 \pm 0.48$ and $34.31 \pm 0.43 \mathrm{~kg})(P<0.05)$. McCarter et al. (1991)
Table 5. Means \pm SE for calf traits by sire breed

\begin{tabular}{lcc}
\hline \hline Sire breed & Birth weight & Weaning weight \\
\hline Boran & $33.55 \pm 0.63^{\mathrm{a}}$ & $213.7 \pm 3.10^{\mathrm{a}}$ \\
Brahman & $33.96 \pm 0.53^{\mathrm{a}}$ & $228.1 \pm 2.37^{\mathrm{b}}$ \\
Tuli & $33.75 \pm 0.58^{\mathrm{a}}$ & $201.6 \pm 2.69^{\mathrm{c}}$ \\
\hline
\end{tabular}

a,b,c Within traits (columns), means that do not share a common superscript differ $(P<0.05)$.

noted that in cows from Angus and Hereford dams with various levels of $\mathrm{Br}$ breeding, as age increased from 3 to $5 \mathrm{yr}$ old, birth weights increased significantly. Similarly, Roberson et al. (1986) noted that birth weights of calves increased with age until cows reached $7 \mathrm{yr}$ old and then declined in $\mathrm{Br}$, Hereford, and Brahman-Hereford crosses.

Sex of calf affected birth weight $(P<0.001)$ with female calves being $1.97 \mathrm{~kg}$ lighter, on average, than their male contemporaries. Lemos et al. (1984), although between different breeds than in the current study (Holstein-Friesian and the zebu breed Guzera), found differences in birth weight of $4.7 \mathrm{~kg}$ between males and females with $1 / 4$ of their genes from Holstein-Friesian, which were by Guzera bulls, when compared with only $0.8-\mathrm{kg}$ difference between males and females for the other 5 groups with different fractions of Holstein-Friesian in the study (all by predominantly HolsteinFriesian bulls). This range would include the differences in the current study. The interaction of dam breed of cow and sex of the calf was also important $(P=0.01)$. In calves from cows with Angus dams, males were $2.90 \mathrm{~kg}$ heavier than females. Male calves from cows with Hereford dams were $1.48 \mathrm{~kg}$ heavier than the females. There were no differences $(P>0.05)$ between male calves from the 2 types of dams, but female calves from cows with Hereford dams were $1.01 \mathrm{~kg}$ heavier $(P=0.03)$ than those from cows with Angus dams. 
Weaning weight. Sire breed of cow was a source of variation $(P<0.01)$ for weaning weight, but dam breed of cow was not $(P=0.76)$. Means for sire breed of cow were all different from one another $(P<0.05)$, with Br-sired cows weaning the heaviest calves $(228.1 \pm 2.37 \mathrm{~kg})$, T-sired cows weaning the lightest $(201.6 \pm 2.69 \mathrm{~kg})$, and Bo-sired cows intermediate for weaning weight $(213.7 \pm 3.10 \mathrm{~kg})$ presented in Table 5. When the cows in the current study were analyzed as calves with their half-sib brothers, Herring et al. (1996) reported that Br-sired calves $(234.3 \mathrm{~kg})$ were significantly heavier than Bo-sired $(217.1 \mathrm{~kg})$ and T-sired calves $(209.1 \mathrm{~kg})$, which were not significantly different from each other.

In Cycle $\mathrm{V}$ of the Germplasm Evaluation Program (GPE), Br, Bo, and T bulls (along with other breeds) were mated to Hereford, Angus, and MARC III (1/4 each Angus, Hereford, Red Poll, and Pinzgauer) cows (Cundiff et al., 2000). Those authors observed that the second and subsequent calves by Charolais and $\mathrm{F}_{1}$ Belgian Blue bulls and from Br-sired cows had significantly heavier 200-d weights $(234.5 \mathrm{~kg})$ than those from Bo-sired cows $(221.8 \mathrm{~kg})$ and T-sired cows $(214.1 \mathrm{~kg})$.

\section{Cow Traits}

Weight. Sire breed of cow was important $(P<0.01)$, and Br-sired cows were heavier than both Bo-sired and T-sired cows, which were not different from one another. This is presented for mature cows at $7 \mathrm{yr}$ of age in Table 6. Differences $(P=0.03)$ due to sire breed $\times$ dam breed interaction were also present. Regardless of dam breed, Br-sired females were heavier than Bo-sired and T-sired females. Note, however, Br-sired females from Angus cows were heavier than those from Hereford dams by $31.9 \mathrm{~kg}(P=0.02)(606 \pm 11.20$ vs. $574 \pm 10.28 \mathrm{~kg}$, respectively), but Bo-sired and

Table 6. Means and SE for cow weight and BCS at $7 \mathrm{yr}$ of age (1999 and 2000 for 1992- and 1993-born cows, respectively)

\begin{tabular}{lcc}
\hline \hline Sire breed & Cow weight $(\mathrm{kg})$ & Cow BCS \\
\hline Boran & $505.8 \pm 10.46^{\mathrm{a}}$ & $6.3 \pm 0.130^{\mathrm{a}}$ \\
Brahman & $590.5 \pm 8.35^{\mathrm{b}}$ & $6.0 \pm 0.104^{\mathrm{a}}$ \\
Tuli & $508.5 \pm 9.37^{\mathrm{a}}$ & $5.8 \pm 0.116^{\mathrm{b}}$ \\
Lactation status & & \\
$\quad$ Lactating & $506.5 \pm 4.88^{\mathrm{y}}$ & $5.35 \pm 0.060^{\mathrm{y}}$ \\
$\quad$ Nonlactating & $563.3 \pm 12.66^{\mathrm{z}}$ & $6.70 \pm 0.161^{\mathrm{z}}$ \\
\hline
\end{tabular}

\footnotetext{
${ }^{\mathrm{a}, \mathrm{b}}$ Within traits (columns), means for sire breed that do not share a common superscript differ $(P<0.05)$.

${ }^{y, z}$ Within traits (columns), means for lactation status that do not share a common superscript differ $(P<0.05)$.
}

T-sired females from Angus dams were not heavier than those from Hereford cows $(509 \pm 14.17 \mathrm{~kg}$ for Bo-Angus vs. $503 \pm 13.63 \mathrm{~kg}$ for Bo-Hereford and $520 \pm 11.61 \mathrm{~kg}$ for T-Angus vs. $497 \pm 12.03 \mathrm{~kg}$ for T-Hereford). Although not significant $(P=0.11)$, $\mathrm{T}$-sired females from Hereford cows were slightly heavier than those from Angus cows as $7 \mathrm{yr}$ olds $(520 \pm 11.61$ vs. $497 \pm 12.03 \mathrm{~kg}$, respectively). This could be attributed to the presence of a dilution gene in $\mathrm{T}$ cattle. There were a small number (exact number unrecorded) of Tuli-Angus females that were smokey colored and had rat tails (similar to some Simmental-cross cattle) that appeared to have lower performance and longevity within the current study (note that not all of the smokey colored TuliAngus were rat tailed and that some of these nonrat tailed smokey Tuli-Angus cows were among the most productive cows in the study; similarly, not all smokey colored Simmental-Angus crosses are rat tailed). Schalles and Cundiff (1999) described this rat-tail condition in Continental cross cattle (primarily with Angus and Holstein) as short, curly, malformed, and sometimes sparse hair and lack of hair on the switch, and note that breeders have reported various performance losses from none to severe. Although rat-tailed calves were not different from non-rat-tailed calves at birth or 205-d weight in their study, lower average daily gains in the winter from weaning to yearling $(P=0.01)$ and thus, $19 \mathrm{~kg}$ lighter at $365 \mathrm{~d}(P=0.03)$ and $36 \mathrm{~kg}$ lighter $(P=0.01)$ and 13 -d older $(P=0.15)$ at slaughter.

Lactation status of the cow was also an important source of variation for cow weight $(P<0.01)$. As expected, nonlactating cows among all breeds were heavier than those that were lactating (Table 6).

Body condition score. Sire breed of cow was important $(P=0.002)$ for BCS, with Bo-sired and Br-sired females having higher adjusted means than T-sired females (Table 6). Dam breed of cow was not important $(P=0.26)$. Also, Herring et al. (1996), in the first evaluation of the cows in the present study, noted that Bo-sired heifers had the highest BCS as yearlings (5.53), but they were not significantly different from $\mathrm{T}$-sired yearling heifers (5.33). Brahman-sired yearling heifers had significantly lower average BCS (5.09) than both the Bo-sired and T-sired females.

Similarly, Freetly and Cundiff (1997) evaluated the growth and reproduction characteristics of Br-sired, Bo-sired, and T-sired heifers from Angus and Hereford dams under 2 different nutritional levels. They observed that at breeding, heifers by Bo bulls had higher BCS (7.6) than those by $\mathrm{Br}(7.0)$ 
and T (7.0) bulls. In this same study, BCS was evaluated on the same females at palpation $65 \mathrm{~d}$ following breeding. The authors reported that there were significant differences between the BCS of females from each of the 3 sire breeds with Bo-sired heifers the highest (6.6), followed by Br-sired heifers (6.4) and then T-sired heifers (6.0).

Lactation status of the cow was also an important source of variation in cow BCS $(P<0.01)$. Similarly to cows being heavier when not lactating, females that were not nursing a calf had higher BCS than those that were (Table 6).

\section{Longevity Aspects}

Cow survival. Each cow in this project had a complete, uncensored survival (longevity) record. No differences by year of birth or dam breed (Angus or Hereford) were detected for cow survival. Bo-sired cows had greater $(P<0.05)$ mean survival age $(12.72 \pm 0.83 \mathrm{yr})$ than Br-sired (11.06 $\pm 0.57 \mathrm{yr})$ and T-sired cows (10.64 $\pm 0.59 \mathrm{yr})$.

Most cows $(76.92 \%)$ left the herd for reproductive failure when compared to other reasons (Table 7). Cows with 2 failures to wean a calf before $14 \mathrm{yr}$ of age and 1 failure at or after that age was cause for removal. Boran-sired females were culled due to reproductive failure less frequently $(66.67 \%)$ than Br-sired (83.63\%) and T-sired (76.92\%) females.

Undiagnosed death, only behind reproductive failures, was the second highest reason for culling a cow. These undiagnosed deaths were instances where the cows were found dead, but there was no definite cause identified. Any number of assumptions could be made as to the cause of these deaths, but no necropsy was done on these animals. More T-sired cows died or were culled for other health reasons than Br-sired or Bo-sired cows.

Incisor condition score. Sire breed of cow was important $(P=0.01)$; Br-sired and Bo-sired females had higher incisor condition scores than T-sired females, but were not different from each other (Table 8). Age category of the cow nested within birth year was also important $(P<0.01)$.

In model 2, cows with broken or smooth mouths were assigned a value of 0 , and cows with solid mouths were assigned a value of 1 . Sire breed of cow was again important $(P=0.03)$ in explaining the variation of incisor condition scores. In this model, the adjusted mean for Br-sired females was higher than $\mathrm{T}$-sired females. Boran-sired females were intermediate to cows sired by $\mathrm{Br}$ and $\mathrm{T}$ bulls, but were not significantly different from either. Bailey (1991) found that $\mathrm{Br}$ cross cows had more mating seasons, gave birth to more calves, and weaned more progeny than Hereford, Red Poll, $\mathrm{F}_{1}$ Hereford-Red Poll, $F_{1}$ Angus-Hereford, $F_{1}$ AngusCharolais, and $F_{1}$ Red Poll-Hereford females. This could coincide with Br-sired females, as found in the current study, having sounder mouths and is supported by Núñez-Dominguez et al.'s (1991) assessment that cows with less than sound mouths may need more time to eat under range conditions limiting their ability to meet their full nutritional needs for ideal BCS.

Riley et al. (2001) evaluated 14-yr-old cows for incisor condition scores using these same models. The authors reported means slightly higher than those found in the current study for both model equivalents. For $B$. indicus $\mathrm{F}_{1}$ cows evaluated with model 1 , means ranged from 0.92 to 1.01 , whereas those evaluated with model 2 ranged from 0.32 to 0.57 .

In summary, Bo-sired cows had an advantage in reproductive rates compared to $\mathrm{Br}$-sired and $\mathrm{T}$-sired females. Calves from $\mathrm{Br}$-sired cows were heavier than those from Bo-sired and T-sired cows throughout the study. This advantage in weaning weight of calves from Br-sired cows might partially offset lower reproductive rates and higher maintenance requirements. Boran-sired and T-sired cows weighed less than Br-sired cows. Tuli-sired cows weaned the lightest calves and had the most tooth

Table 7. Numbers of cows that were removed from the herd by sire breed and reason for removal ${ }^{1,2}$

\begin{tabular}{lccccccc}
\hline \hline Sire breed & Reproductive failure & Udder & Lameness $^{3}$ & Prolapse & Died & Other $^{4}$ & Total $^{\text {Pan }}$ \\
\hline Brahman & 46 & 1 & 3 & 1 & 4 & 0 & 55 \\
Boran & 24 & 2 & 4 & 2 & 3 & 1 & 36 \\
Tuli & 40 & 0 & 2 & 0 & 7 & 3 & 52 \\
Total removed & 110 & 3 & 9 & 3 & 14 & 4 & 143 \\
\hline
\end{tabular}

${ }^{1}$ The criterion for removal of cows from the project was 2 failures to wean a calf before $14 \mathrm{yr}$ of age, and 1 failure at or after that age.

${ }^{2}$ Counts did not differ from $\chi^{2}$ expectation $(P>0.05)$.

${ }^{3}$ Three of these cows (1 Boran-, 1 Brahman-, and 1 Tuli-sired cow) were also open but classified as removed because of lameness as that was the primary reason for leaving the herd.

${ }^{4} \mathrm{All}$ in this category except for a single Tuli-sired cow with a jaw abnormality were associated with eye cancer. 
Table 8. Incisor condition scores by sire breed for 2 different models

\begin{tabular}{lcc}
\hline \hline Sire breed & Model $1^{1}$ & Model $2^{2}$ \\
\hline Brahman & $0.76 \pm 0.054^{\mathrm{a}}$ & $0.34 \pm 0.083^{\mathrm{a}}$ \\
Boran & $0.71 \pm 0.052^{\mathrm{a}}$ & $0.23 \pm 0.090^{\mathrm{a}, \mathrm{b}}$ \\
Tuli & $0.54 \pm 0.058^{\mathrm{b}}$ & $0.01 \pm 0.091^{\mathrm{b}}$ \\
\hline
\end{tabular}

${ }^{\mathrm{a}, \mathrm{b}}$ Within traits (columns), means that do not share a common superscript differ $(P<0.05)$.

${ }^{1}$ Means represent proportions of cows with complete or partial sets of incisors.

${ }^{2}$ Means represent proportions of cows with complete sets of incisors.

wear and deterioration with age, which could have led to their shorter productive lives. These results lead us to believe that the potential for Bo-British crossbred cows in the Southern United States is very high as their maternal performance was superior in a number of areas to that of Br-British and T-British cows therefore offering the opportunity for greater production efficiency.

\section{LITERATURE CITED}

Bailey, C. M. 1991. Life span of beef-type Bos taurus and Bos indicus $\times$ Bos taurus females in a dry, temperate climate. J. Anim. Sci. 69:2379-2386. doi:10.2527/1991.6962379x

Beef Improvement Federation (BIF). 2010. Guidelines for uniform beef improvement programs. 9th ed. http:// beefimprovement.org/content/uploads/2013/07/MasterEdition-of-BIF-Guidelines-Updated-12-17-2010.pdf (Accessed 8 May 2015.)

Cartwright, T. C. 1980. Prognosis of Zebu cattle: research and application. J. Anim. Sci. 50:1221. doi:10.2527/ jas1980.5061221x

Chase, C. C., Jr, D. G. Riley, T. A. Olson, S. W. Coleman, and A. C. Hammond. 2004. Maternal and reproductive performance of Brahman $\times$ Angus, Senepol $\times$ Angus, and Tuli $\times$ Angus cows in the subtropics. J. Anim. Sci. 82:2764-2772. doi: $10.2527 / 2004.8292764 x$

Cundiff, L. V., K. E. Gregory, T. L. Wheeler, S. D. Shackelford, M. Koohmaraie, H. C. Freetly, and D. D. Lunstra. 2000. Preliminary results from cycle V of the cattle germplasm evaluation program at the Roman L. Hruska U.S. Meat Animal Research Center. Progress Report 19. Roman L. Hruska U.S. Meat Animal Research Center, USDA, Clay Center, NE.

Federation of Animal Science Societies (FASS). 2010. Guide for the care and use of agricultural animals in research and teaching. FASS, Champaign, IL.

Freetly, H. C., and L. V. Cundiff. 1997. Postweaning growth and reproduction characteristics of heifers sired by bulls of seven breeds and raised on different levels of nutrition. J. Anim. Sci. 75:2841-2851. doi:10.2527/1997.75112841x
Freetly, H. C., and L. V. Cundiff. 1998. Reproductive performance, calf growth, and milk production of first-calf heifers sired by seven breeds and raised on different levels of nutrition. J. Anim. Sci. 76:1513-1522. doi: $10.2527 / 1998.7661513 x$

Gaughan, J. B., T. L. Mader, S. M. Holt, M. J. Josey, and K. J. Rowan. 1999. Heat tolerance of Boran and Tuli crossbred steers. J. Anim. Sci. 77:2398-2405. doi:10.2527/1999.7792398x

Gilmour, A. R., B. J. Gogel, B. R. Cullis, and R. Thompson. 2009. ASReml user guide release 3.0. VSN Int. Ltd., Hemel Hempstead, UK.

Herring, A. D., J. O. Sanders, R. E. Knutson, and D. K. Lunt. 1996. Evaluation of $F_{1}$ calves sired by Brahman, Boran, and Tuli bulls for birth, growth, size, and carcass characteristics. J. Anim. Sci. 74:955-964. doi:10.2527/1996.745955x

Hetzel, D. J. S. 1988. Comparative productivity of the Brahman and some indigenous Sanga and Bos indicus breeds of East and Southern Africa. Anim. Breed. Abstr. 56:243-255.

Lemos, A. M., R. L. Teodoro, R. T. Barbosa, A. F. Freitas, and F. E. Madalena. 1984. Comparative performance of six Holstein-Friesian $\times$ Guzera grades in Brazil. 1. Gestation length and birth weight. Anim. Prod. 38:157-164. doi:10.1017/S0003356100002142

McCarter, M. N., D. S. Buchanan, and R. R. Frahm. 1991. Comparison of crossbred cows containing various proportions of Brahman in spring or fall calving systems: III. Productivity as three-, four-, and five-year olds. J. Anim. Sci. 69:2754-2761. doi:10.2527/1991.6972754x

Núñez-Dominguez, R., L. V. Cundiff, G. E. Dickerson, K. E. Gregory, and R. M. Koch. 1991. Heterosis for survival and dentition in Hereford, Angus, Shorthorn and crossbred cows. J. Anim. Sci. 69:1885-1898. doi:10.2527/1991.6951885x

Paschal, J. C., J. O. Sanders, and J. L. Kerr. 1991. Calving and weaning characteristics of Angus-, Gray Brahman-, Gir-, Indu-Brazil-, Nellore-, and Red Brahman-sired $\mathrm{F}_{1}$ calves. J. Anim. Sci. 69:2395-2402. doi:10.2527/1991.6962395x

Phillips, W. A., R. P. Wetteman, S. W. Coleman, and J. W. Holloway. 2005. Evaluation of Boran, Tuli, Gelbvieh, and Brahman $F_{1}$ crosses in Oklahoma. In: Southern Cooperative Series Bulletin. 405:176-181.

Riley, D. G., J. O. Sanders, R. E. Knutson, and D. K. Lunt. 2001. Comparison of $F_{1}$ Bos indicus $\times$ Hereford cows in central Texas: II. Udder, mouth, longevity, and lifetime productivity. J. Anim. Sci. 79:1439-1449. doi: $10.2527 / 2001.7961439 x$

Roberson, R. L., J. O. Sanders, and T. C. Cartwright. 1986. Direct and maternal genetic effects on preweaning characters of Brahman, Hereford and Brahman-Hereford crossbred cattle. J. Anim. Sci. 63:438-446. doi:10.2527/ jas1986.632438x

Schalles, R. R., and L. V. Cundiff. 1999. Inheritance of the "rat-tail" syndrome and its effect on calf performance. J. Anim. Sci. 77:1144-1147. doi:10.2527/1999.7751144x

USDA. 2017. Statistics by state. http://www.nass.usda.gov (Accessed 4 June 2017.) 